University of Nebraska - Lincoln

DigitalCommons@University of Nebraska - Lincoln

1980

\title{
Stress Measurements at Depth in the Vicinity of the San Andreas Fault: Implications for the Magnitude of Shear Stress at Depth
}

Mark D. Zoback

U.S. Geological Survey, zoback@stanford.edu

Hiroaki Tsukahara

National Research Center for Disaster Prevention

Stephen Hickman

U.S. Geological Survey

Follow this and additional works at: https://digitalcommons.unl.edu/usgsstaffpub

Part of the Earth Sciences Commons

Zoback, Mark D.; Tsukahara, Hiroaki; and Hickman, Stephen, "Stress Measurements at Depth in the Vicinity of the San Andreas Fault: Implications for the Magnitude of Shear Stress at Depth" (1980). USGS Staff -- Published Research. 402.

https://digitalcommons.unl.edu/usgsstaffpub/402

This Article is brought to you for free and open access by the US Geological Survey at DigitalCommons@University of Nebraska - Lincoln. It has been accepted for inclusion in USGS Staff -- Published Research by an authorized administrator of DigitalCommons@University of Nebraska - Lincoln. 


\title{
Stress Measurements at Depth in the Vicinity of the San Andreas Fault: Implications for the Magnitude of Shear Stress at Depth
}

\author{
MARK D. ZOBACK \\ U.S. Geological Survey, Reston, Virginia 22092 \\ HiRoaki TSUkaHARA \\ National Research Center for Disaster Prevention, Ibaraki, Japan \\ STEPHEN HICKMAN \\ U.S. Geological Survey, Menlo Park, California 94025
}

\begin{abstract}
Using the hydraulic fracturing technique, we have made a systematic series of in situ stress measurements in wells drilled near the San Andreas fault. In an attempt to provide constraints for the magnitude of shear stress on the San Andreas fault at depth we have measured both the variation of stress with distance from the fault in relatively shallow $(\sim 230 \mathrm{~m})$ wells and the variation of stress with depth in a l$\mathrm{km}$-deep well located $4 \mathrm{~km}$ from the fault. The shallow wells are located along profiles roughly perpendicular to the fault in the western Mojave desert near Palmdale and in central California where the fault is creeping. In both areas the direction of maximum compression was found to be approximately $45^{\circ}$ from the local trend of the San Andreas. The two stress profiles show very similar results: (1) shear stress (on planes parallel to the San Andreas) increases with distance from the fault, more markedly in the western Mojave, (2) the far-field shear stress at $\sim 200 \mathrm{~m}$ depth is $\sim 50$ bars, and (3) the horizontal principal stresses as well as shear stress increase with depth more rapidly in the wells farthest from the fault. The $\sim 1-\mathrm{km}$-deep well, also located in the western Mojave desert, shows increases of both horizontal principal stresses and shear stress with depth. Shear stress increases from about 25 bars at 150-300 m to about 80 bars at $750-850 \mathrm{~m}$. Although this rapid increase of shear stress with depth suggests that the mean shear stress on the fault at seismogenic depths exceeds several hundred bars, the principal stresses increase with depth in a steplike manner. As this may be a near-surface effect, extrapolation of the measurements to much greater depths may not be warranted.
\end{abstract}

\section{INTRODUCTION}

Understanding the physical mechanisms controlling slip on the San Andreas fault is impeded by our uncertainty of the magnitude of the shear stresses acting on the fault at depth. This paper describes a series of in situ measurements that were made near the San Andreas fault to address this problem in two ways. First, we attempted to estimate the magnitude of shear stress on the fault at depth by measuring the variation of shear stress with distance to the fault at relatively shallow depth. Thermomechanical models of the San Andreas fault system developed by Lachenbruch and Sass [1973] demonstrated that the variation of shear stress with distance from the fault can be indicative of the stress on the fault at depth. Accordingly, the hydraulic fracturing technique was used to make stress measurements in wells $\sim 230 \mathrm{~m}$ in depth that were drilled along profiles roughly perpendicular to the fault; one profile was located in the western Mojave desert near Palmdale, where the San Andreas has been locked since the 1857 great earthquake, and the other profile was located in the Gabilan range of central California, where aseismic creep and small magnitude earthquakes characterize the fault's behavior. The Mojave profile data were briefly discussed by Zoback and Roller [1979]. Second, we measured the variation of shear stress with depth in a 1-km-deep hole that was drilled at one of the sites of the Mojave profile located about $4 \mathrm{~km}$ from the fault.

This paper is not subject to U.S. copyright. Published in 1980 by the American Geophysical Union.
The purpose of this paper is twofold: to evaluate the reliability and consistency of hydraulic fracturing stress measurements and to examine the implications of the measurements made near the San Andreas for the magnitude of shear stress on the fault at depth.

\section{Experimental Sites}

The locations of the wells in the western Mojave desert are shown in Figure 1. The wells are all approximately $240 \mathrm{~m}$ deep. Wells Moj. 2, 4, and 5 (located 4, 22, and $34 \mathrm{~km}$ from the San Andreas, respectively) were drilled in quartz monzonite of Cretaceous age. The location of outcrops in the area largely determined the siting of the holes. The 1-km-deep hole mentioned earlier (designated hole XTLR) was drilled at the same site as Moj. 2. Well Moj. 1, located $2 \mathrm{~km}$ southwest of the San Andreas fault, was drilled into the Punchbowl formation, a well-indurated nonmarine sedimentary rock of Miocene age.

In central California the stress measurements were made in wells drilled in Cretaceous age quartz monzonite of the Gabilan range (Figure 2). These wells are about $220 \mathrm{~m}$ deep and are located 2, 4, and $14 \mathrm{~km}$ from the San Andreas (wells LKB, LKC, and LKD, respectively). No wells were drilled between LKC and LKD because of anticipated topographic effects on the stress field.

\section{Hydraulic Fracturing}

The hydraulic fracturing technique was used to measure in situ stresses because it is the only technique that can be used 


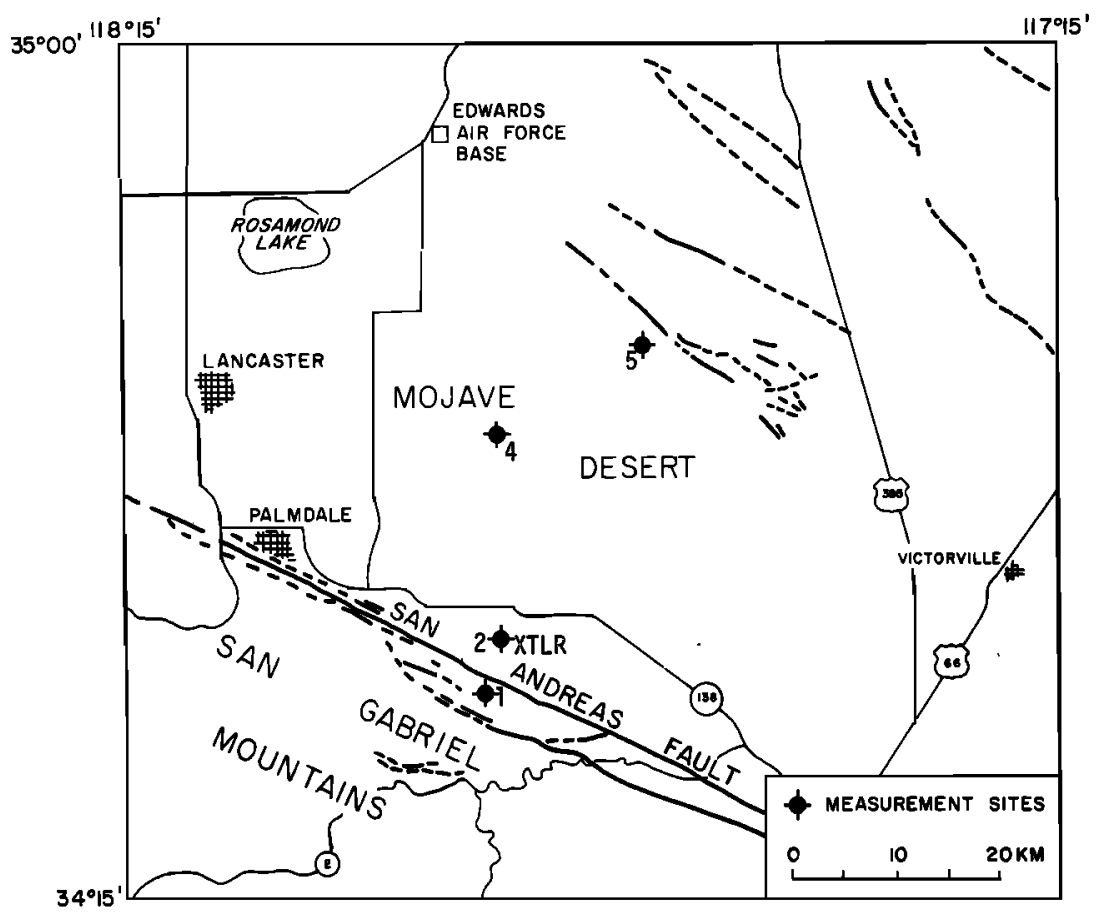

Fig. 1. Location of wells used for stress measurements in the western Mojave desert near Palmdale. The wells north of the San Andreas fault were located at sites where granitic rock outcrops. Well Moj. 2 and XTLR are located within $20 \mathrm{~m}$ of each other.

efficiently in holes greater than a few meters deep. Thus measurements can be made at significant distances from stress-relieved surfaces. The hydraulic fracturing technique has been described by a number of investigators [see Haimson and Fairhurst, 1970]. Basically, it is assumed that one principal stress is vertical and that the propagation of hydraulic fractures from a vertical borehole is perpendicular to' $S_{h}$, the least horizontal principal stress [Hubbert and Willis, 1957]. The assumption that the fracture propagates perpendicular to the least principal stress is well supported by the excellent agreement between hydrofrac-, geologic-, and seismologically determined stress field indicators [see Zoback and Zoback, 1980]. McGarr and Gay [1978] have presented data supporting the validity of the assumption of an approximately vertical principal stress direction resulting from the lithostatic load.

The horizontal principal stresses are determinable from (1)

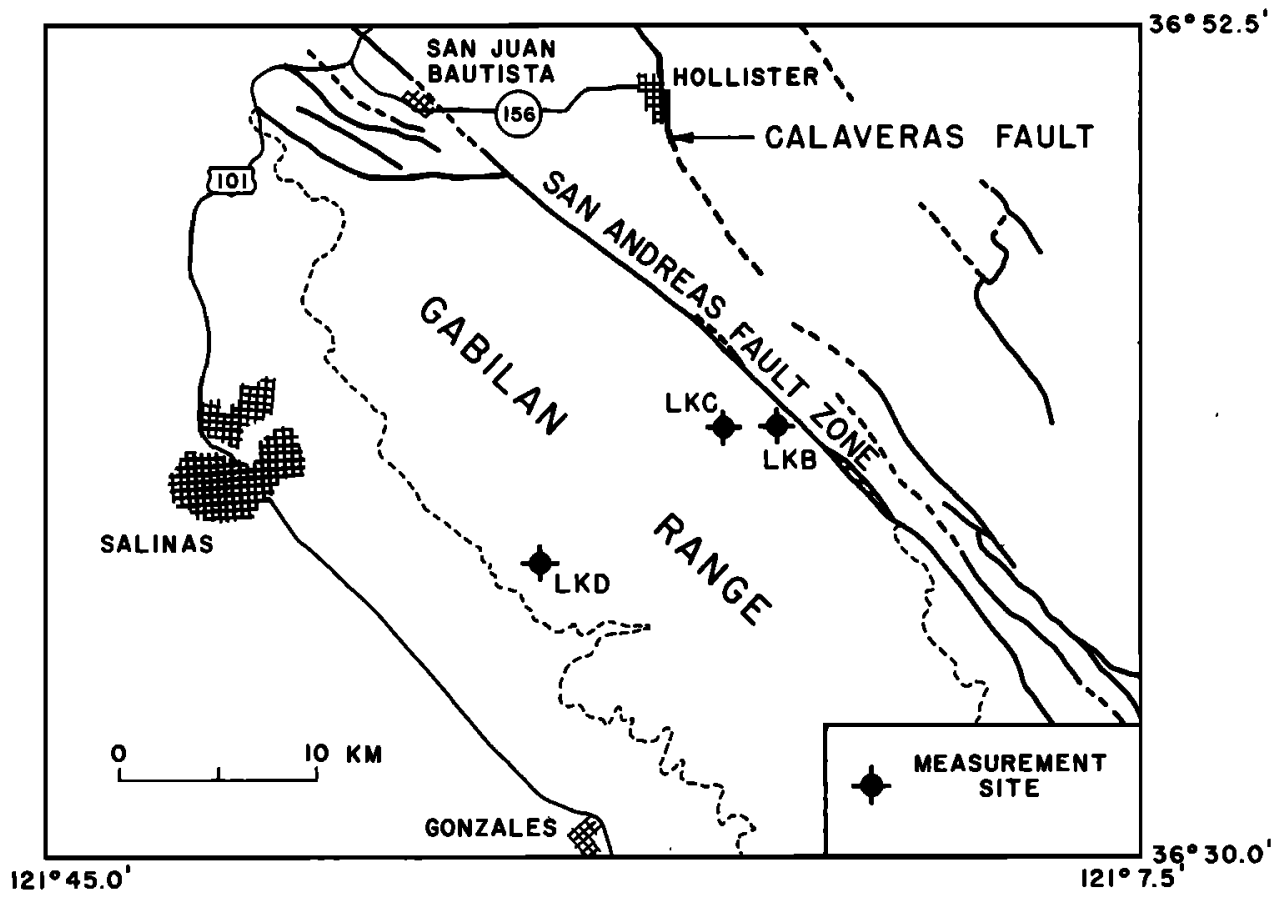

Fig. 2. Measurement sites composing the central California profile. No sites were selected between LKC and LKD because of anticipated topographic effects. 


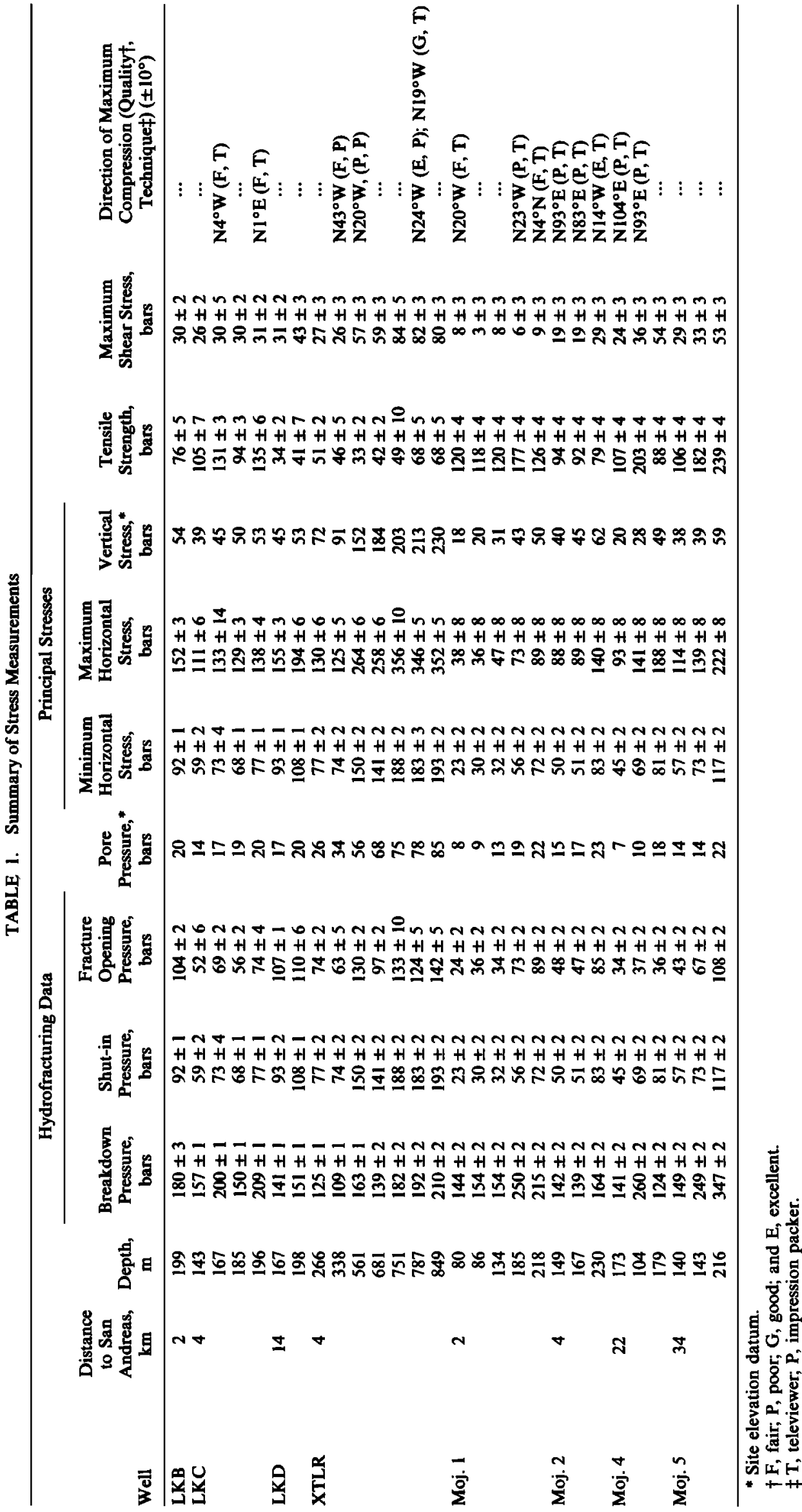



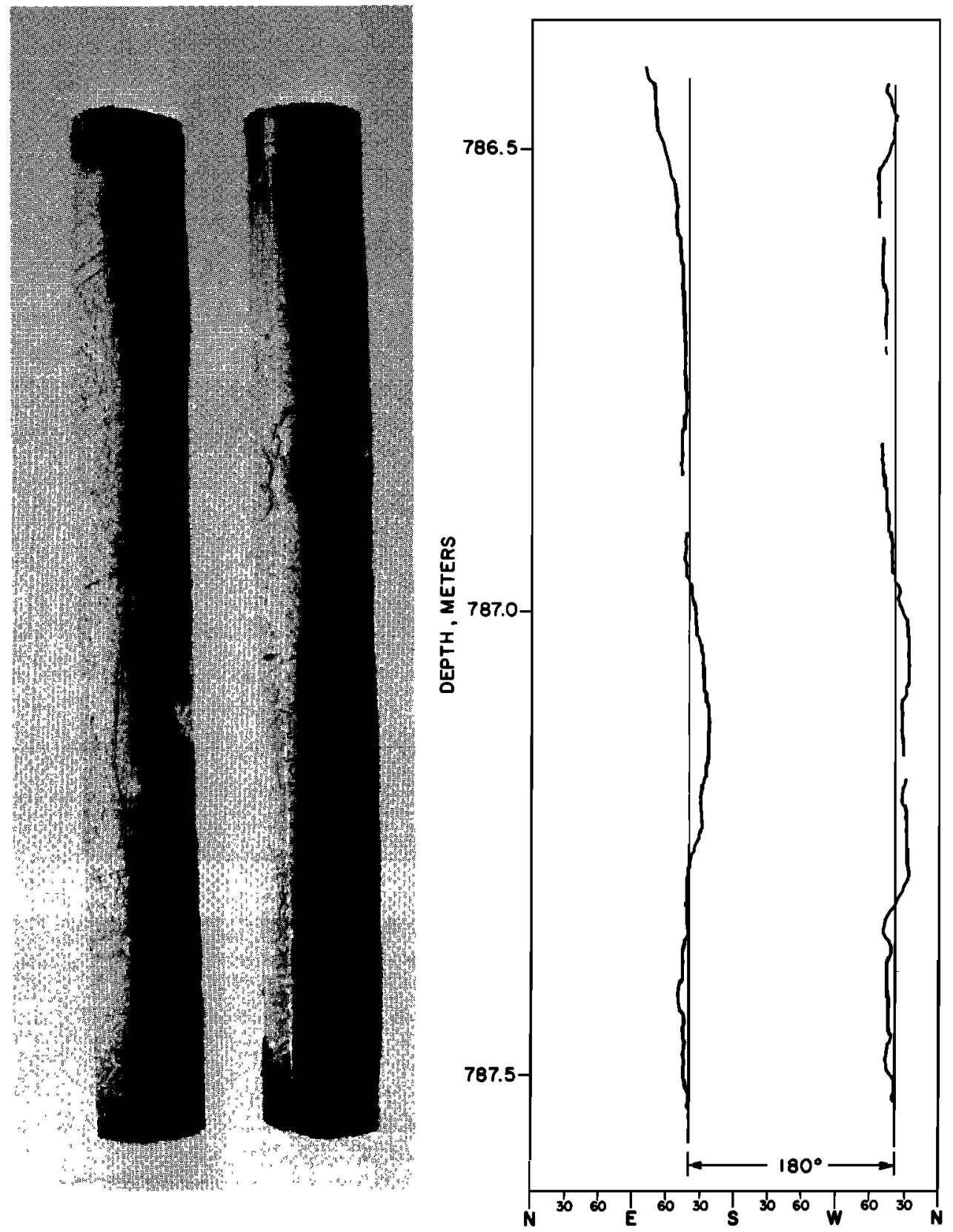

Fig. 3. Photographs of impression packer from the hydraulic fracture at $787 \mathrm{~m}$ in well XTLR and interpretive line drawing. The line drawing is oriented with respect to magnetic north for comparison with the televiewer record in Figure 4.

the pressure necessary to induce (or open) a vertical hydraulic fracture at the borehole and (2) the pressure at which the hydraulically isolated (shut-in) fracture comes to equilibrium. Determination of $S_{H}$, the maximum horizontal principal stress, requires the assumption of elastic behavior in the region surrounding the borehole. Although in many cases this assumption is clearly not valid and $S_{H}$ cannot be determined [cf. Zoback et al., 1977], this is not considered to be a problem in this study because nearly all the measurements were made in crystalline rock.

Hubbert and Willis [1957] derived the formula

$$
P_{b}=3 S_{h}-S_{H}-P_{p}+T
$$

relating the breakdown, or fracture formation pressure $P_{b}$ to the horizontal principal stresses $S_{h}$ and $S_{H}$, the pore pressure $P_{p}$, and the tensile strength $T$, of the formation. When core is available for determination of $T$, an estimate of $S_{H}$ can be made using (1). In this study we use somewhat unconventional techniques for determination of $S_{h}$ and $S_{H}$. First, rather than only using the instantaneous shut-in pressure (ISIP) for determination of $S_{h}$, we considered also the shut-in pressures from a number of pressurization cycles as well as the low-flow-rate pumping pressure on those cycles. Second, in the manner of Bredehoeft et al. [1976] we used the pressure at which the already formed fracture opened at the well bore to accept fluid and set $T=0$ in (1) to compute $S_{H}$. No core was available for tensile strength determinations, but as laboratory-determined tensile strength values can be inconsistent, we consider this to be at least as reliable a method. Haimson [1978] found good results with this method in a case when $T$ was available and $S_{H}$ could be computed both ways. A more detailed rationale for this method is discussed by Zoback and Pollard [1978].

The azimuth of the maximum horizontal principal stress 
can be determined from the orientation of the hydraulic fracture at the well bore. After drilling each hole a careful survey was made with an ultrasonic borehole televiewer [see Zemanek et al., 1970] to locate intervals without natural fractures for the hydrofrac tests. The same tool was used to inspect the borehole after fracturing to determine the orientation of and hence the azimuth of $S_{H}$. In well XTLR an oriented impression packer was also used to determine the azimuth of $S_{H}(A n-$ derson and Stahl [1967] illustrate and discuss the use of impression packers).

\section{RESULTS}

The results of the fracture orientations are summarized in Table 1 with an indication of the quality of the determination as well as the technique that was used. Figures 3 and 4 show a comparison of a borehole televiewer record of a hydraulic fracture (from $230 \mathrm{~m}$ deep in well Moj. 2) with a conventional

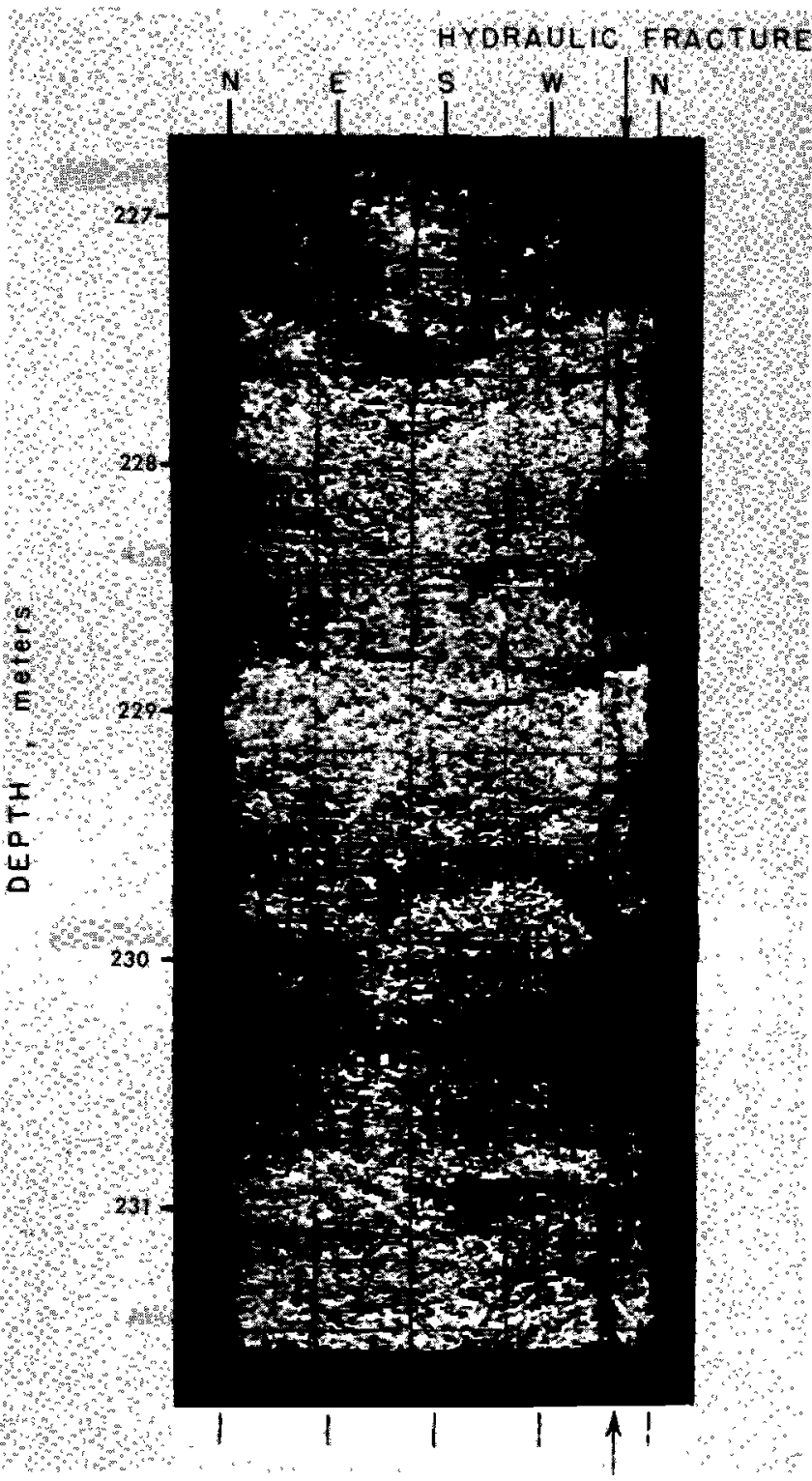

Fig. 4. Borehole televiewer record and interpretative line drawing for the hydraulic fracture at $230 \mathrm{~m}$ in well Moj. 2 . The televiewer displays (as brightness) the amplitude of an acoustic pulse reflected off the borehole wall as a function of depth and azimuth (with respect to magnetic north). Note the excellent correspondence of the fracture azimuth from this interval with that shown in Figure 3. impression packer of the 787-m interval in well XTLR. For comparison both records are referenced to magnetic north (the televiewer trace is triggered at magnetic north by a flux gate magnetometer), and the impression packer is represented by a line drawing. In this case the results of both techniques compare quite favorably (see Table 1) and show that the direction of maximum compression is about $\mathrm{N}^{\circ} 0^{\circ} \mathrm{W}$.

Values of the fracture azimuth given in Table 1 are accurate to about $\pm 10^{\circ}$, although it should be realized that the fractures denoted by a 'P' (poor), may not be fractures at all. The measurements in Moj. 1, the deeper measurement in Moj. 2, and two of three fracture impressions in XTLR indicate that near the San Andreas fault in the western Mojave the direction of $S_{H}$ is about $\mathrm{N} 20^{\circ} \mathrm{W} \pm 15^{\circ}$. The fracture azimuths in Moj. 1 at depths of 80,86 , and $134 \mathrm{~m}$ previously reported by Zoback et al. [1980] were in error due to an instrument malfunction. In central California the data from well LKC indicates that the direction of $S_{H}$ is about N-S $\pm 10^{\circ}$. Thus in both areas the fracture directions indicate that the direction of maximum horizontal compression is about $45^{\circ}$ from the strike of the San Andreas fault. This agrees well with available geologic data and fault plane solutions in the areas [see Zoback and Zoback, 1980].

The pressure and flow rate records for all of the successful stress measurements are shown in the appendix, and the data pertinent to these records are given in Table 1 . The pressure data shown in the appendix were recorded with a pressure transducer located on the surface, although the values given in the table were primarily taken from a subsurface pressure gauge located in the hydrofrac interval. Both gauges are of comparable accuracy, but the subsurface gauge is not contaminated by the pressure drop in a high pressure hose between the surface transducer and the wellhead. This pressure drop was typically about 10 bars. Because the subsurface pressure recordings are quite small and are read with a microscope, they are not suitable for reproduction.

The pressure and flow data from $185 \mathrm{~m}$ in LKC of the central California profile (Figure 5) is typical. The breakdown pressure is clear and distinct at a subsurface pressure of 150 bars. Pumping was stopped and the well was shut-in immediately after breakdown. A fairly distinct ISIP can be seen in the record. After shut-in, the pressure in the fracture is allowed to vent, resulting in the flow back (negative flow rate) shown in the records. On secondary pressurization cycles the shut-in pressure is repeatedly observed; a value of 68 bars (subsurface pressure) was determined for $S_{h}$. Distinct curvature during pressure buildup on the secondary pressurization cycles indicates that the fracture is opening to accept fluid. This pressure was found to be 56 bars (subsurface). Progressively more fluid is pumped on each cycle and correspondingly more flow back occurred. As the flow back rate rapidly diminished with time, we ended the flow back period after 3-4 min. The pressure buildup after the last cycle results from momentarily 'choking' the flow back valve.

When the least principal stress is vertical, a vertical hydraulic fracture will form at the borehole when using an inflatable straddle packer [see Haimson and Fairhurst, 1970]. As it propagates, however, the fracture will tend to turn into a horizontal plane, and as this occurs, the long-term shut-in pressure approaches the value of the vertical stress $S_{v}$. Zoback et al. [1977] discussed this phenomenon at greater length, and the same phenomena has been observed by other investigators (B. C. Haimson, oral communication, 1979). As the least principal stress was vertical in many cases reported here, this behavior 


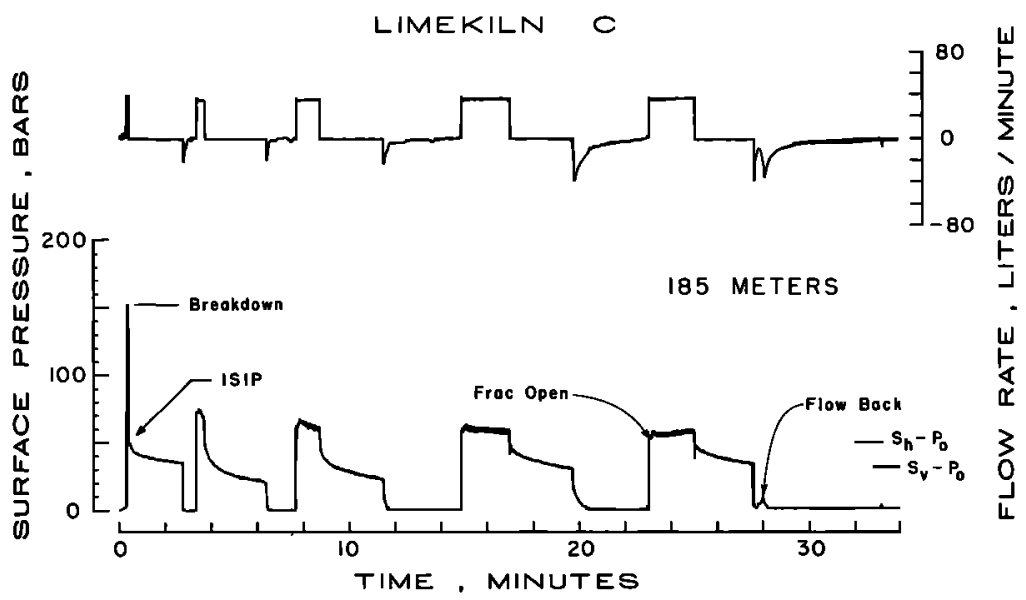

Fig. 5. Surface pressure and flow records from the hydraulic fracture at $185 \mathrm{~m}$ in well LKC. The manner in which the principal stresses are determined from the pressure data is discussed in the text. Positive flow rate represents injection into the hydrofrac interval; negative flow rate is flow out of the hydrofrac when the surface pressure is vented. The small pressure pulse after the fifth cycle results from 'choking' the flow back valve.

is seen in the pressure-time record shown in Figure 5, and it is a common characteristic of many of those presented in the appendix.

In the case of the deeper measurements made at XTLR a distinct breakdown pressure is not observed because of the relatively high value of the least principal stress with respect to the breakdown and fracture-opening pressures. By using carefully controlled and (as nearly as possible) constant flow rates both the breakdown and fracture-opening pressures can be determined fairly accurately. This is illustrated by the record from $786 \mathrm{~m}$ at XTLR (Figure 6). Although breakdown is not manifested by a sudden drop in pressure on the first pumping cycle, the nearly constant rate of well bore pressurization can clearly be seen to change abruptly when the fracture forms. As shown in Figure 6, the fracture-opening pressure can be determined from the secondary pumping cycles in a similar way because the flow rate (and hence the initial rate of well bore pressurization) was the same on each of the cycles. As demonstrated by the XTLR data presented in the appendix, the type of record shown in Figure 5 gradually becomes the type shown in Figure 6 as the least principal stress increases with depth relative to the breakdown pressure.

The magnitude of the least and greatest horizontal principal stresses, $S_{h}$ and $S_{H}$, determined from the hydrofrac data are summarized in Table 1 and presented in Figures 7, 8, and 10. The error bars in these data reflect the uncertainty with which a given shut-in or fracture-opening pressure could be determined and thus represent only the precision of the determination. It should be reiterated that measurements are omitted in which something went wrong with the experiment: if a preexisting fracture opened, if the inflatable packer failed to seal the hydrofrac interval, or if a leak occurred in the packer, drill pipe, or pumping system, for example. A measure of the repeatability of these determinations is provided by measurements made at similar depths, which agree quite well.

The number of measurements attempted in each well was controlled by the number of fracture-free intervals that could be found. Unfortunately, very few measurements could be attempted in some of the wells because of the extremely dense fracturing; only one successful measurement was made in LKB and two in LKD (Figure 8). The natural fractures encountered in the wells are analysed and discussed elsewhere
(D. A. Seeburger and M. D. Zoback, manuscript in preparation, 1980).

Figures 7 and 8 show the magnitude of the greatest and least principal stress with respect to the lithostatic stress in the wells composing the two profiles. As there are a number of striking similarities in the manner in which the principal stresses vary with depth and distance from the San Andreas

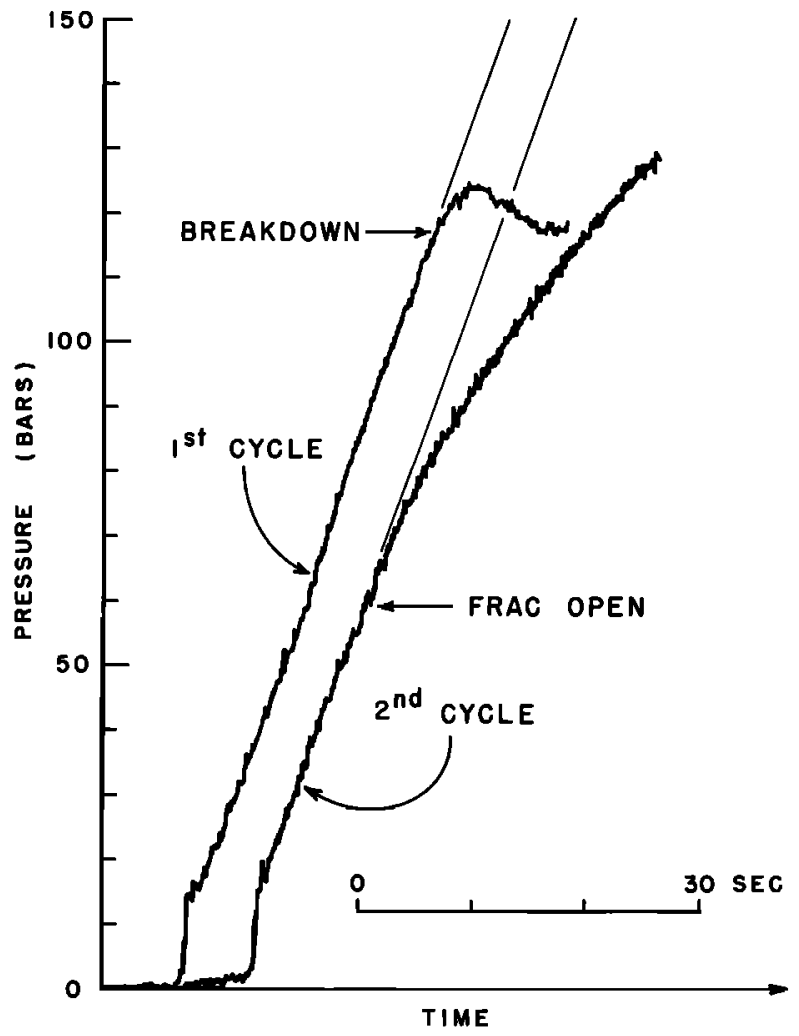

Fig. 6. The beginning of the first and second pressurization cycles from the fracture at $787 \mathrm{~m}$ in well XTLR (see Figure A4b for the entire record). As the flow rate was nearly constant during pressurization and the same on both cycles, the deviation of the pressure buildup curve from a constant rate of pressurization is diagnostic of fracture formation on the first cycle and fracture opening on subsequent cycles. 

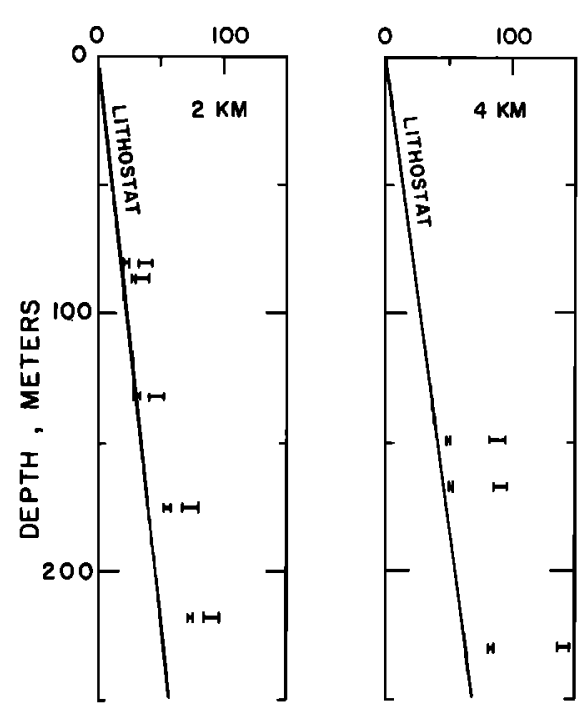

STRESS, BARS

Fig. 7. The maximum and minimum principal horizontal compressive stresses $\left(S_{H}, S_{h}\right)$ for the wells in the western Mojave desert. The smaller and larger error bar represents $S_{h}$ and $S_{H}$, respectively. Moj. 1, 2, 4, and 5 are located at distances from the San Andreas of 2, 4, 22, and $34 \mathrm{~km}$. The solid line in each graph represents the vertical principal stress.

fault, the characteristics of these data can be summarized as follows:

1. Like many stress measurements made at similarly shallow depths [McGarr and Gay, 1978], both horizontal principal stresses exceed the lithostat in all of the profile wells. In well XTLR (Figure 10) the lithostat is the intermediate principal stress (as expected in strike slip faulting regions) only at depths greater than $300 \mathrm{~m}$.

2. In all the profile wells the magnitude of both horizontal principal stresses increases with depth.
3. Both the magnitude of the principal stresses and the rate at which they increase with depth is greater in the wells further from the fault.

4. At all depths the difference between the horizontal principal stresses, which is proportional to shear stress, increases with distance from the fault.

5. Shear stress appears to increase with depth, most markedly in the wells farthest from the fault.

6. The far-field value of shear stress at $200 \mathrm{~m}$ depth is fairly similar in both profiles.

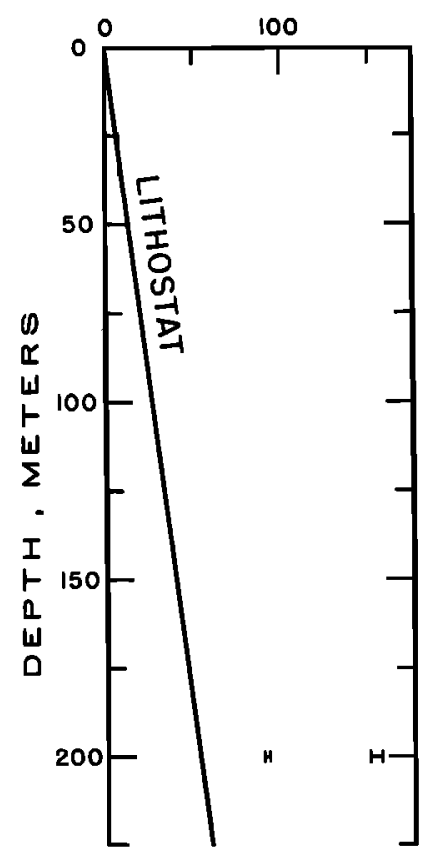

LIMEKILN B

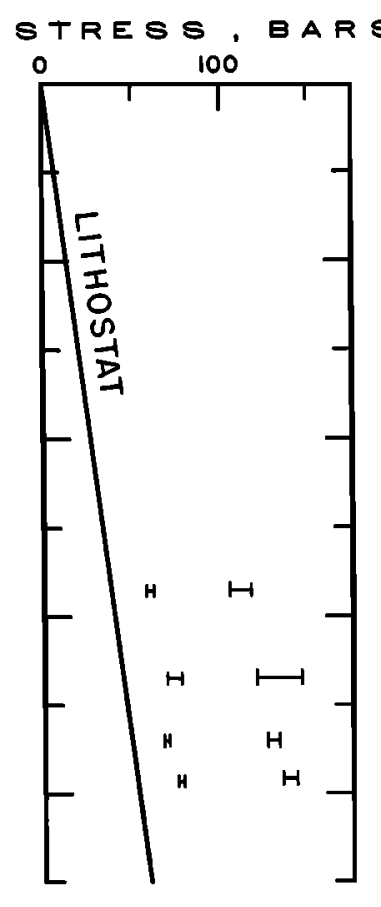

LIMEKILN C

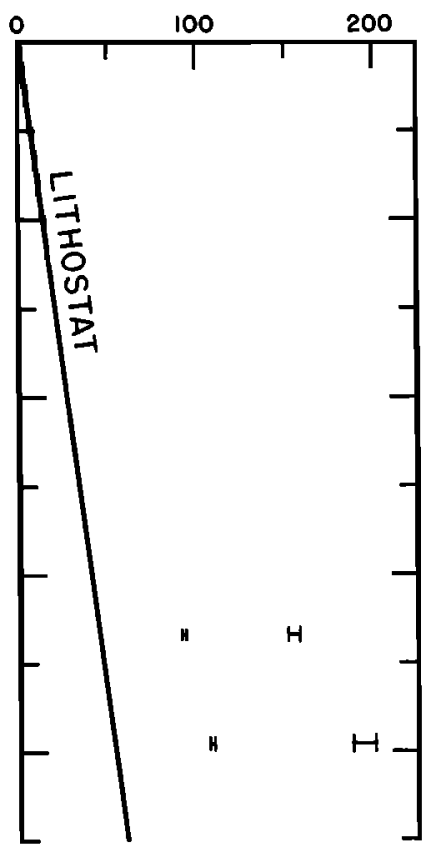

LIMEKILN D

Fig. 8. The horizontal principal stresses determined in the wells of the central California profile. As in Figure 7, the smaller and larger error bars represent $S_{h}$ and $S_{H}$, respectively. The wells LKB, LKC, and LKD are located 2, 4, and 14 $\mathrm{km}$ from the San Andreas, respectively. The very few measurements in LKB and LKD are the result of the numerous natural fractures encountered in the wells. 


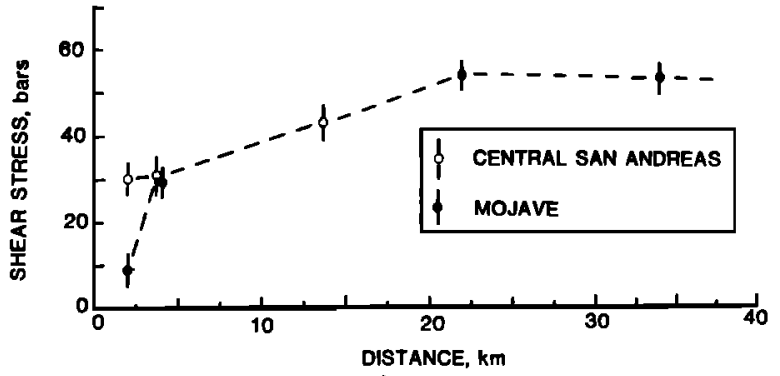

Fig. 9. Shear stress resolved onto planes parallel to the San Andreas fault as a function of distance to the fault. All measurements were made at a depth of $200 \mathrm{~m}$. As the direction of maximum compression was found to be at $45^{\circ}$ from the San Andreas in both areas, the shear stress was taken simply to be $\frac{1}{2}\left(S_{H}-S_{h}\right)$.

Figure 9 shows the variation of horizontal shear stress with distance to the San Andreas fault from the profile measurements at approximately 200 -m depth. As the observed orientation of $S_{H}$ is about $45^{\circ}$ to the San Andreas, the shear stress acting on planes parallel to the San Andreas was simply taken to be half the difference between the horizontal principal stresses. The magnitude of shear stress measured at $\sim 200-\mathrm{m}$ depth in both profiles is apparently about the same at distances greater than $\mathbf{4} \mathbf{~ k m}$ from the fault. Along both profiles, shear stress at $\sim 200 \mathrm{~m}$ seems to increase from about 30 bars at $4 \mathrm{~km}$ to about 55 bars at approximately $20 \mathrm{~km}$. The primary difference in the two profiles is the magnitude of shear stress in the well closest to the fault; the shear stress at a distance of $2 \mathrm{~km}$ in the central California profile is about 30 bars (the same as at $4 \mathrm{~km}$ ), whereas that at the same distance in the Mojave profile is only about 10 bars. It should be pointed out that the data point at $2 \mathrm{~km}$ in the Mojave profile (Moj. 1) differs from that reported by Zoback and Roller [1979] because they mistakenly reported $S_{H}-S_{h}$ rather than $\frac{1}{2}\left(S_{H}-S_{h}\right)$ for that particular well.

Figure 10 shows the results of the stress measurements made in the $\sim 1-\mathrm{km}$ deep well, XTLR. As it was drilled at the same location as Moj. 2, the data from Moj. 2 (depths of 149, 167 , and $230 \mathrm{~m}$ ) are included in Figure 10 and agree well with the data from greater depths. Significant characteristics of these data are (1) the vertical principal stress is intermediate in value at depths greater than $300 \mathrm{~m}$, (2) the magnitude of the horizontal principal stresses clearly increase with depth, and (3) shear stress (half the difference between the horizontal principal stresses) increases from about 25 bars at $150-300 \mathrm{~m}$ to about 80 bars at 750 to $850 \mathrm{~m}$.

The horizontal principal stresses and shear stress increases in a steplike manner with depth in XTLR. $S_{h}, S_{H}$, and $\tau$ are fairly constant at depths above $350 \mathrm{~m}$; they are of similar magnitude at $561 \mathrm{~m}$ and $681 \mathrm{~m}$ and similar again below $750 \mathrm{~m}$. A zone of dense fracturing is located between 350 and $500 \mathrm{~m}$ that may explain the fairly significant increase in stress over that interval. The steplike manner of stress increase with depth may thus be some sort of near-surface effect that disappears at greater depth.

\section{DISCUSSION}

\section{Stress Measurements}

The data presented above demonstrate that the state of stress near active faults shows systematic variations. The standardization of field procedures has resulted in significant improvements in the stress measurement technique [see Zoback et al., 1977]. By working primarily in crystalline rocks a variety of operational problems are overcome. The wells were drilled quite efficiently, and they generally remained open without casing for the period of the tests and longer (enabling them to be used for other purposes). Inspection of the wells with a borehole televiewer enabled us to choose the optimal intervals for hydraulic fracturing. Without this, the numerous natural fractures in the wells would have resulted in natural fracture extension rather than hydraulic fracture formation in a great many cases. The natural fractures did prevent us from making many stress measurements in the wells.

The determination of the maximum principal stress is typically more uncertain than the least principal stress because of the possibility of violating the assumption of elastic response of the rock around the well bore and because of uncertainties in interpretation of the pressure-time data. Little difficulty was encountered with the former problem in this study because of the rock type. Figures 7,8 , and 10 indicate that the $S_{H}$ values are about as repeatable as $S_{h}$, lending confidence to the field procedures and interpretive methods we used. Calculated values for tensile strength, the difference between the breakdown and fracture opening pressures, are fairly consistent for a given well (Table 1), certainly well within the laboratory-observed variation for this parameter.

Although the repeatability of the stress measurements is self evident in the data, the absolute accuracy of the stress data

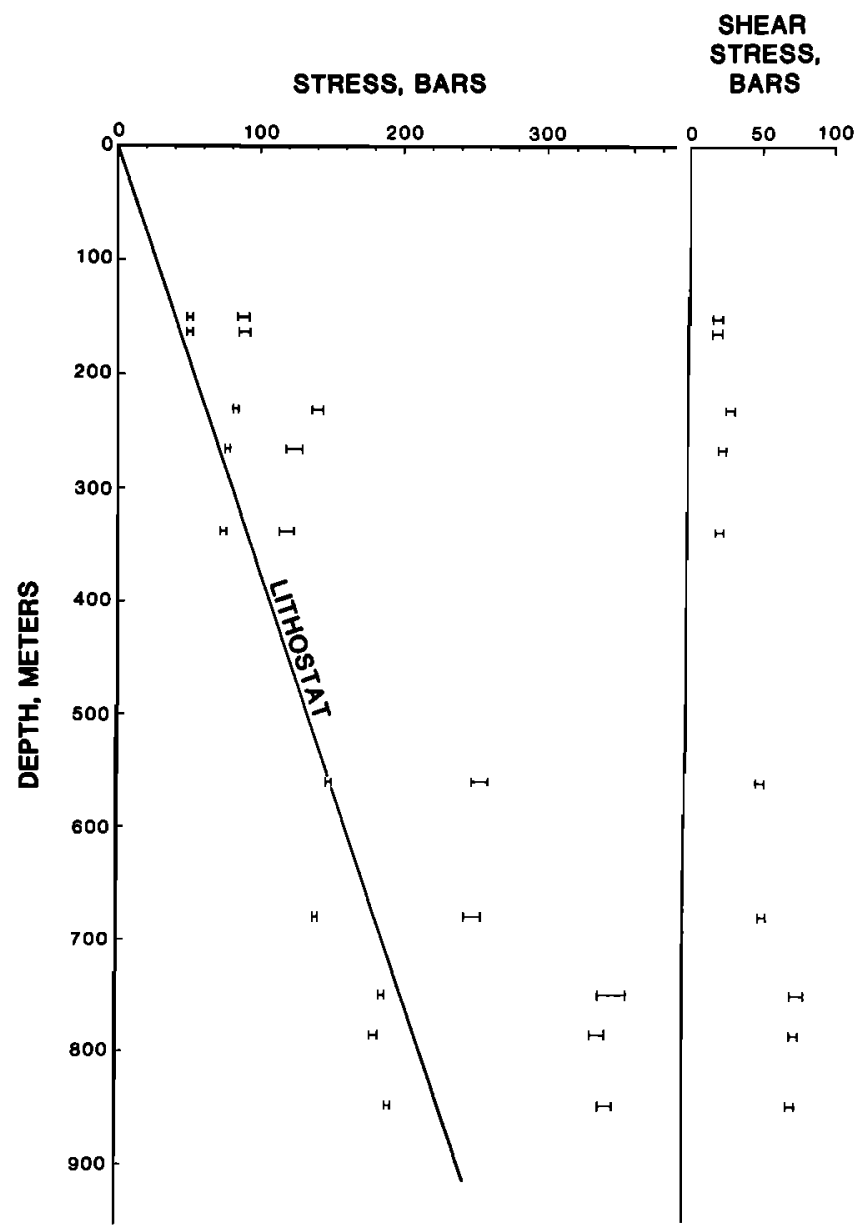

Fig. 10. The horizontal principal stresses and shear stress (resolved onto a plane parallel to the San Andreas) in well XTLR. The measurements at depths of 149,167 , and $230 \mathrm{~m}$ were made in Moj. 2, which is at the same location. 
presented above is nearly impossible to determine independently. Under ideal conditions, hydraulic fracturing and overcoring techniques have given very comparable stress magnitudes [Haimson et al., 1974]. In a compilation of stress measurements, McGarr and Gay [1978] found fairly good agreement between the range of magnitudes determined by hydraulic fracturing and overcoring techniques.

For determining the orientation of the hydraulic fractures the televiewer and impression packer both gave successful results, but each technique has distinct drawbacks. Use of the televiewer was faster, but in many cases the hydraulic fracture was not observed. Moveover, in some cases the presence of a fracture is questionable (those denoted as 'poor' in Table 1); it is not clear that they are, in fact, fractures, or just some mark on the well bore that was not detected before fracturing. Thus it is simply not known if the fracture orientations at shallow depths in Moj. 2 (149 and $167 \mathrm{~m}$ ) actually imply that $S_{H}$ is oriented E-W near the surface. The impression packer technique yielded results that were excellent in the case of the fracture shown in Figure 3, but in other cases it gave much poorer results. However, despite the fact that using an impression packer is quite inefficient compared to the televiewer, it is probably the preferable technique for determining fracture azimuth in crystalline rock.

A comparison can be made between the direction of maximum compression we determined for the western Mojave $\left(\mathrm{N} 20^{\circ} \mathrm{W} \pm 15^{\circ}\right)$ and that determined by near surface overcoring nearby [Sbar et al., 1979; Tullis, 1980]. These two overcoring studies each sampled three sites in the sedimentary rock immediately west of the San Andreas fault (near Moj. 1, Figure 1). The $S_{H}$ directions reported by Tullis [1980] (N44 ${ }^{\circ} \mathrm{W}$ $\pm 3^{\circ}, \mathrm{N} 15^{\circ} \mathrm{W} \pm 14^{\circ}$, and $\mathrm{N} 27^{\circ} \mathrm{W} \pm 2^{\circ}$ ) agree fairly well with this study, whereas those of Sbar et al. [1979] (N57 $7^{\circ}$, N-S, and $\mathrm{N} 31^{\circ} \mathrm{E}$ ) do not. Both overcoring techniques yield $S_{H}$ directions that vary widely in the granitic rocks west of the San Andreas. This is probably due to the dense near-surface fracturing there.

\section{Shear Stress at Depth on the San Andreas Fault}

In this section we consider the implications of the data presented above regarding the magnitude of shear stress on the San Andreas fault at depth. Several models of the San Andreas fault zone are considered which specifically address the stress on the fault in terms of the variation of stress with depth and distance from the fault.

A simple two-dimensional antiplane shear model was used by Zoback and Roller [1979] to analyze the Mojave profile data. This model incorporates an increasing shear stress with depth on a vertical plane to simulate traction on the San Andreas fault. This shear stress is balanced by an opposing shear stress (of the same average magnitude) acting on a vertical plane located about two fault depths $(\sim 40 \mathrm{~km})$ away. The influence of basal shear stresses was not incorporated into the model nor were any body forces. With this model the mean shear stress on the fault is related to the shear stress at shallow depth at distances more than one fault depth away. Measurements made only at shallow depth are sufficient to estimate shear stress on the fault with this model because the predicted far-field shear stress is invariant with depth. (Although this assumption is critical to the model, stress measurements usually indicate an increase of stress with depth.) Nevertheless, Zoback and Roller used the increase in shear stress with distance near the fault (Figure 9) to estimate the increase in stress with depth on the fault and the shear stress measured at about 200 $m$ depth in the distant wells (Moj. 4, 5) to derive the mean stress on the San Andreas. The observed increase in shear stress on the San Andreas. The observed increase in shear stress with depth in Moj. 4, 5 was not predicted by the model and was attributed to dense near-surface fracturing in the upper $\sim 150 \mathrm{~m}$. Although this explanation seemed reasonable on the basis of the Mojave profile data alone (Moj. 2 showed less increase in shear stress with depth than Moj. 4, 5 and it has fewer fractures; Moj. 1 had the fewest fractures of all the wells and showed no discernible increase in shear stress), several aspects of the data from the central California profile and hole XTLR suggest that this interpretation should be reconsidered. First, the increase in shear stress continues at least to depths of 850 $m$ in XTLR, well beyond the depth of near-surface dense fracturing. Second, the data from the central California profile also suggest a substantial vertical gradient in shear stress in the well most distant from the fault (LKD), similar to Moj. 4 and 5. It appears that the data from both profiles may show a vertical shear stress gradient increasing with distance to the fault, although the two measurements in LKD and moderate increase in LKC do not constrain this argument very well, and again, the reliability of vertical stress gradients in the upper $200 \mathrm{~m}$ is questionable.

If an antiplane shear model such as that described above is appropriate for the San Andreas fault, shear stress must stop increasing at some depth greater than that of the existing measurements. If, for the sake of discussion, we consider that it does (as discussed below, extrapolation to depth of present data must be done with caution), there seem to be two implications of the profile data. First, as the shear stress at $\sim 200 \mathrm{~m}$ near the fault is considerably higher in central California, the stress on the fault at shallow depth is apparently higher where the fault is slipping than where it is locked. Second, as the farfield shear stress values are about the same from both profiles, the mean stress on the fault would appear to be about the same along both parts of the fault.

The present shear stress data can be evaluated in terms of fault models based on other geophysical constraints. The lack of a measurable heat flow anomaly at the San Andreas fault has led Lachenbruch and Sass [1980] to propose a thermomechanical model in which the primary resistance to plate motion is a basal drag at the bottom of the seismogenic zone. They limit the average tectonic shear stress on the fault to about 200 bars but point out that this value could be much higher if seismically determined 'apparent stress' estimates are grossly in error. In the Lachenbruch and Sass model the basal drag resisting plate motion has a magnitude of 500-600 bars, and the average shear stress acting on planes parallel to the San Andreas increases rapidly from $\sim 200$ bars at the fault to about $\mathbf{1 5 0 0}$ bars (taken as the limit of the frictional strength of upper crustal rocks with normal fluid pressure) at a distance of about $\mathbf{4 0} \mathrm{km}$ from the fault.

The Lachenbruch and Sass model predicts an average shear stress of about 325 bars over a plate $\sim 14 \mathrm{~km}$ thick at a distance of $\mathbf{4 k m}$ from the San Andreas. Clearly, the rate of shear stress increase observed in XTLR cannot be sustained to depths greater than a few kilometers and still be consistent with the Lachenbruch and Sass model. However, the steplike increase in stress observed in XTLR (Figure 10) makes linearly extrapolating those data to much greater depths unreasonable, and thus it is really not possible to rule out their model on the basis of the data now available. 
An important aspect of the Lachenbruch and Sass model bears on the interpretation of the stress profile data. If, as they propose, a large basal shear stress is acting in the seismogenic zone (within about $40 \mathrm{~km}$ of the fault), equilibrium conditions requires shear stress on planes parallel to the San Andreas to increase rapidly with distance. The increase in shear stress with distance from the fault that is seen on both profiles could then be reflecting a basal shear stress rather than the stress on the fault itself (it could be zero). It would seem therefore that the increase in shear stress with distance from the fault observed in the profile data is consistent in form with that expected from a weak fault-basal drag model, but the Lachenbruch and Sass model would predict a much greater rate of stress increase with distance from the fault than that which is observed.

Hanks [1980] has proposed an alternate explanation of the Mojave profile data that is consistent with kilobar level shear stresses on the San Andreas fault. In his model the low shear stress close to the fault in the Mojave results from the stress drop of the great 1857 Fort Tejon earthquake. In a similar way the relatively high shear stress near the fault in central California can be explained by the absence of a great earthquake in this region. As this model is consistent with a strong fault model, it is also consistent with the apparently high shear stresses measured in XTLR.

If the Hanks model is correct, stress profile data have important implications for determining where a given area along the fault happens to be in the earthquake cycle. For example, Hanks assumed that at the time of the 1857 earthquake, shear stress at 200-m depth was invariant with distance to the fault and thus of approximately equal magnitude to the far-field stress measured in Moj. 4, 5 ( 25 bars). Hanks was able to match the Mojave profile data by a process of essentially subtracting the 1857 stress drop and adding stress that has presumably accumulated since 1857 . He estimated that about half the 1857 stress drop has reaccumulated. However, if one assumes that at the time of the 1857 earthquake there was a moderate increase of shear stress with distance from the fault (like that observed on the central California profile), one would conclude that a much larger percentage of the stress drop has reaccumulated.

It is clearly not now possible to choose between the models discussed above. McGarr [1980] and Hanks [1980] point out the nonuniqueness of evaluating the stresses at the boundaries of some idealized fault model from a few stress measurements of limited extent (especially with respect to depth). For a specific model it is necessary to know both the lateral and vertical shear stress gradient to constrain the boundary stresses. This implies that profile measurements such as those described above should be made in wells at least $1 \mathrm{~km}$ deep. Stress measurements in holes $2-5 \mathrm{~km}$ deep near the fault would greatly constrain possible interpretations of the data.

\section{CONCLUding REMARKS}

This work demonstrates that systematic measurements of the variation of stress near the San Andreas fault can provide important information about the fault's behavior. The increase of shear stress with depth in well XTLR appears to be too high to be consistent with mean shear stresses on the fault of only 100-200 bars. However, the steplike manner in which stress is observed to increase with depth in the well clearly demonstrates that extrapolation of the data to greater depths is not warranted. The shallow profile measurements can be explained with both low and high shear stress fault models. Future stress measurements along profiles should be made to depths of $1 \mathrm{~km}$ and greater to get below the near-surface zone of dense fracturing and to constrain the vertical as well as lateral variation of shear stress. Although the measurements made to date do not resolve the issue of the magnitude of shear stress on the fault, there is considerable reason to believe that future measurements may help do so.

\section{APPENDIX \\ Central California Profile}

The pressure and flow data from the central California profile of wells are presented in Figures A1-A3. These records were digitally recorded from an uphole pressure transducer. Downhole pressure is obtained by adding the hydrostatic head (see Table 1) and subtracting the pressure drop that occurs in a hose located between the transducer and the wellhead (10 bars at $35 \mathrm{l} / \mathrm{min}$ ). At the flow rates involved, no appreciable pressure drop occurs in the drill pipe. Notable characteristics of the pressure and flow records are the following.

$L K B 199 \mathrm{~m}$. This record is much like that shown in Figure 4 except that the shut-in pressure is not easy to observe until the third cycle. Again, the long-term shut-in pressure approaches the lithostat. Note that only a small portion of the injected fluid returns to the well bore.

LKC $143 \mathrm{~m}$. Breakdown occurred on the second pressurization cycle at a slightly lower pressure than on the first cycle. This is not a common occurrence, but it has been seen in previous tests and by other investigators. Again, little flow back is observed. The rapid pressure drop during shut-in indicates a minor leak in the system. This can also be seen in some of the other records.

$L K C 167 \mathrm{~m}$. An unusual reduction in the shut-in pressure can be seen on the fifth and sixth pressurization cycles. As repeatable shut-in pressures are required for a reliable stress measurement, the shut-in pressure and fracture opening pressure are taken from the previous cycles. The resultant stress determinations agree well with the other values in the well (see Figure 7).

$L K D 167 \mathrm{~m}$. Breakdown occurred on the second pressurization cycle as in the 143-m test in LKC. The small difference

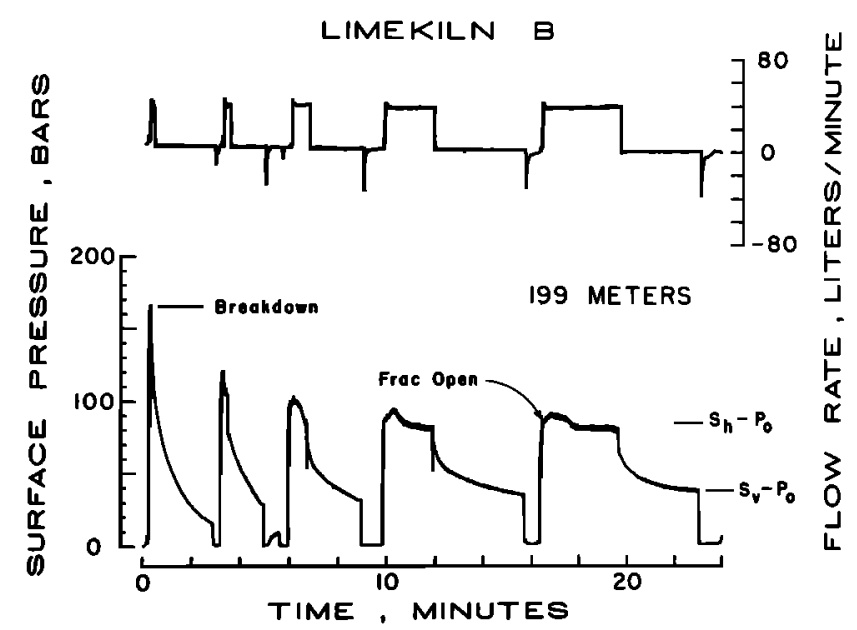

Fig. A1. Pressure and flow record from 199-m depth in well LKB. Record from $185 \mathrm{~m}$ is shown in Figure 5. 
LIMEKILN C
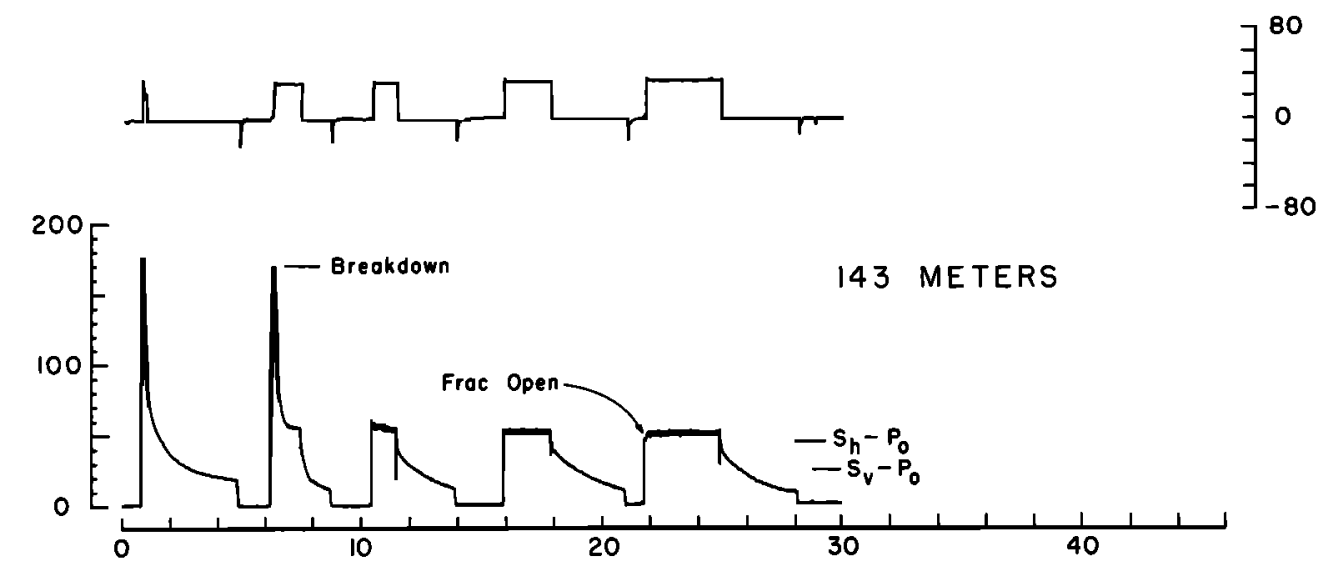

80
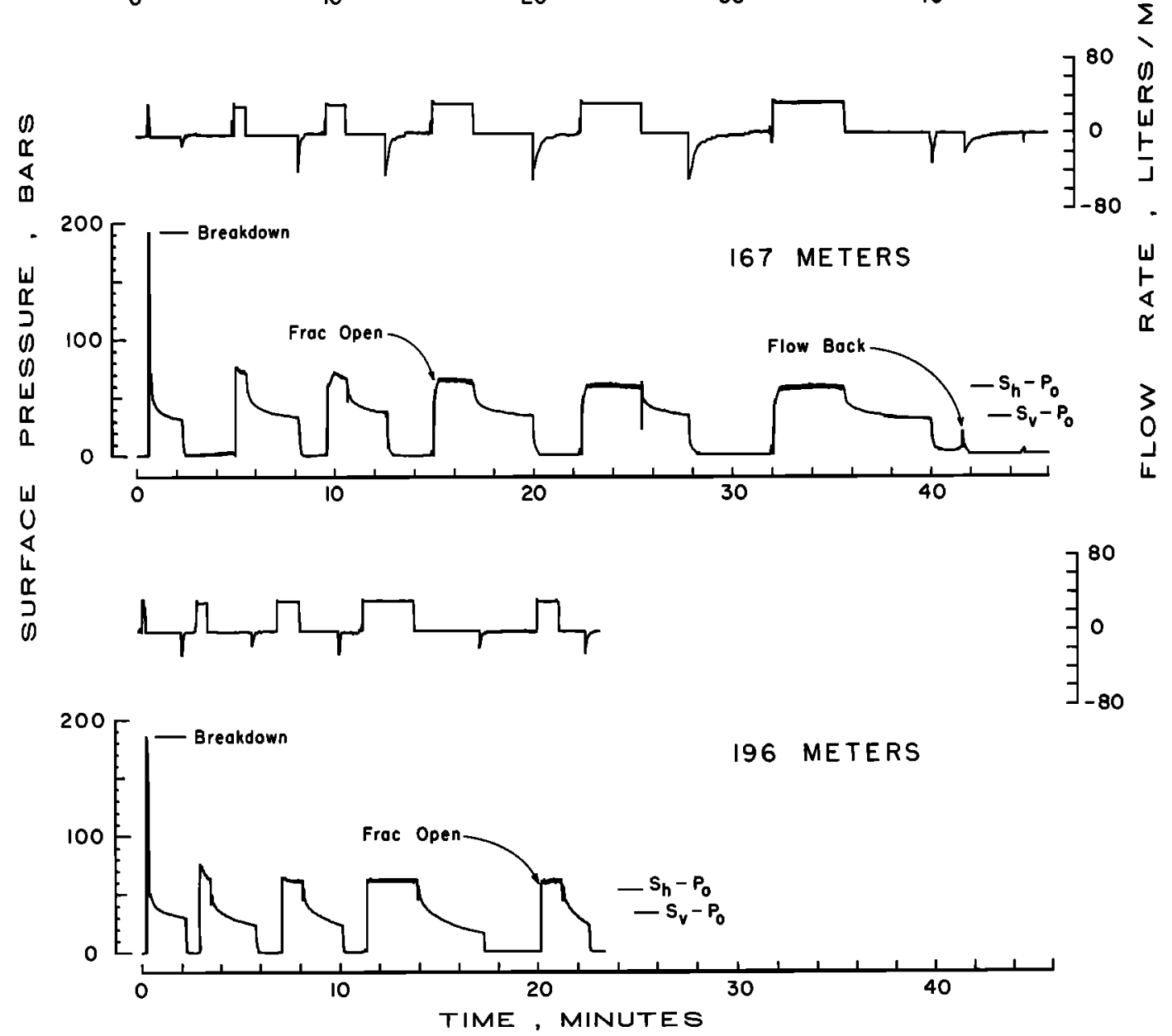

Fig. A2. Pressure and flow records from 143-, 167-, and 196-m depths in well LKC. 


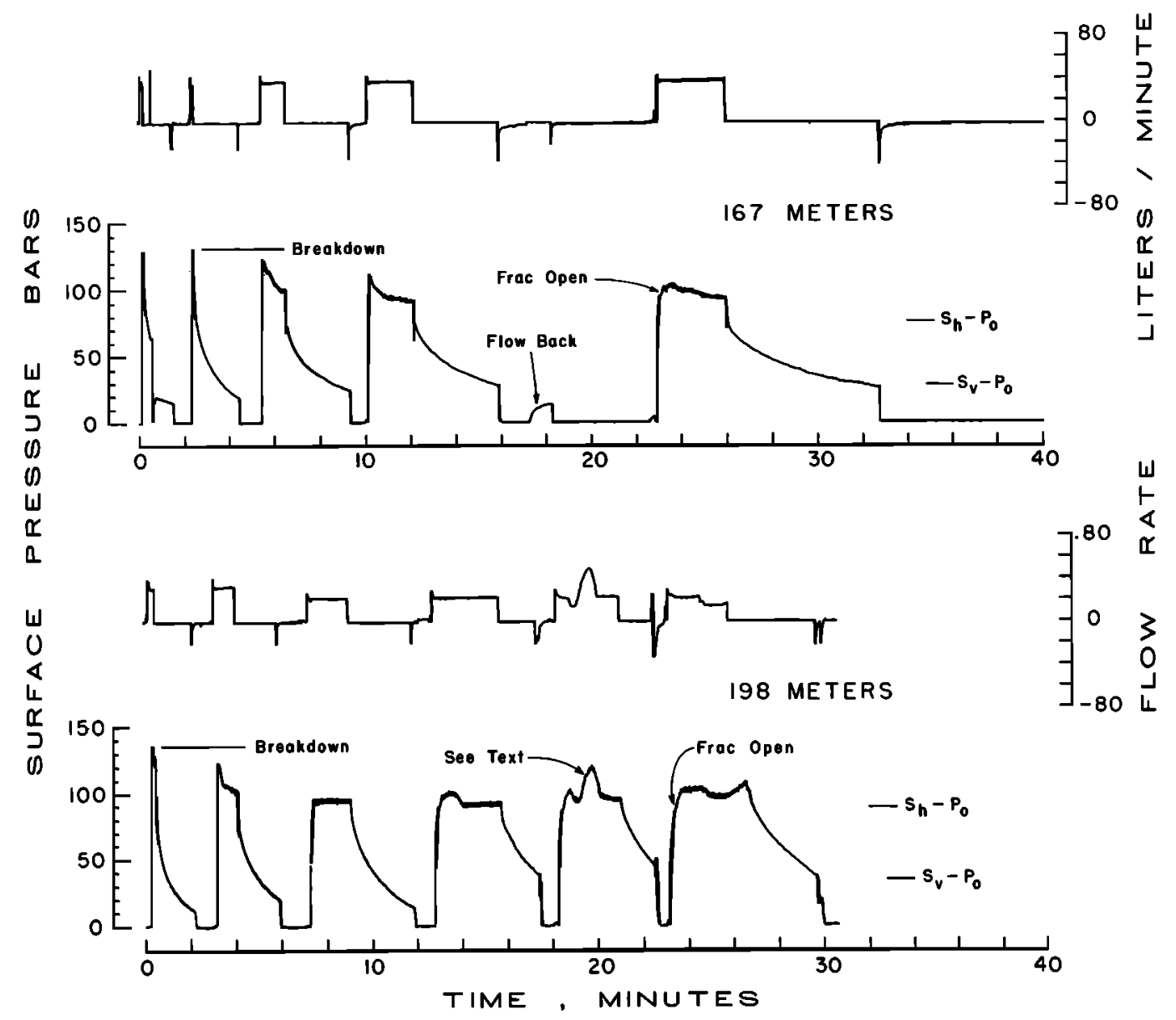

Fig. A3. Pressure and flow records from 167- and 198-m depths in well LKD.

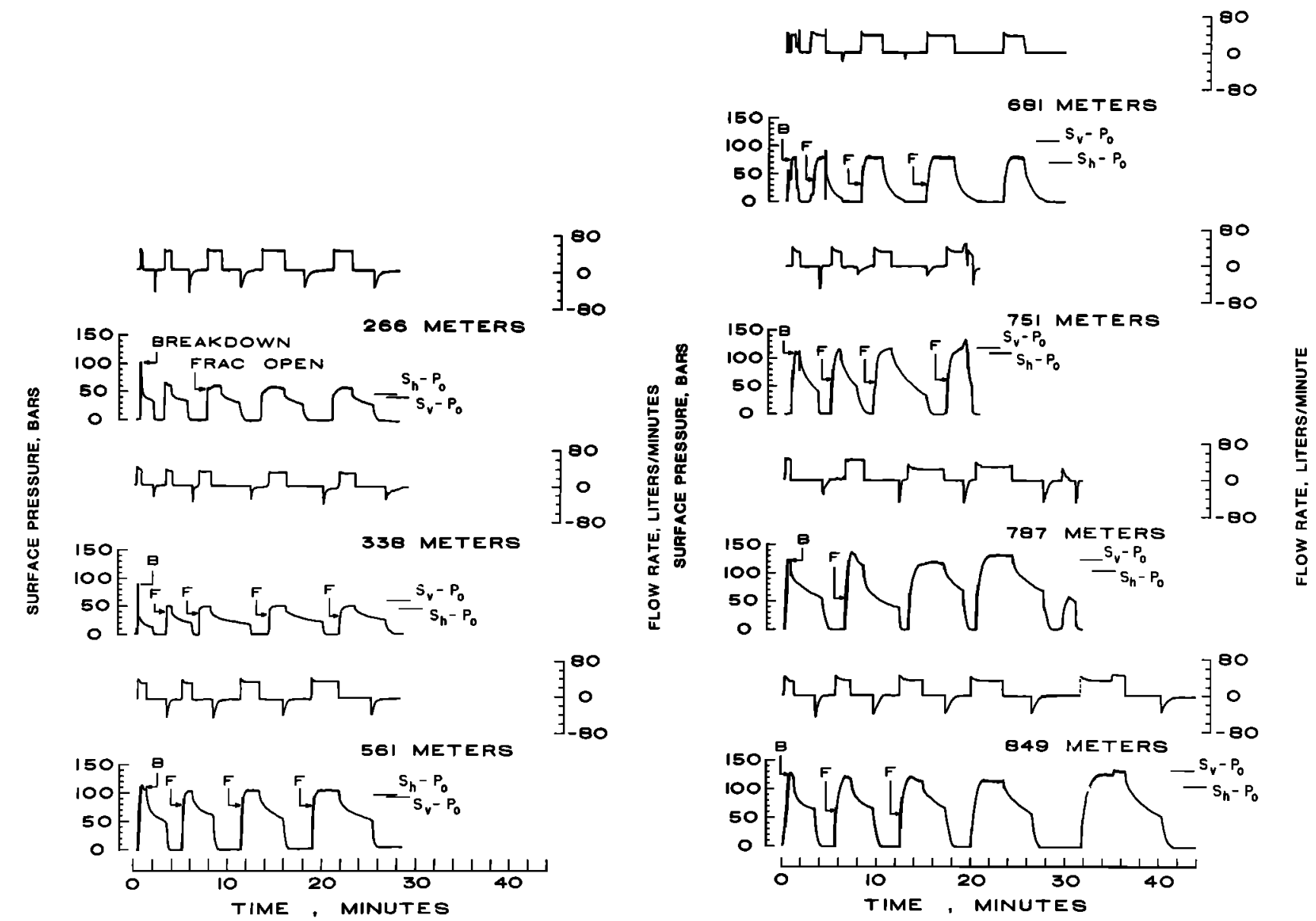

Fig. A4a. Pressure and flow records from 266-, 338-, and 561-m depths in well XTLR.

Fig. A4b. Pressure and flow records from 681-, 751-, 786-, and 849m depths in well XTLR. 

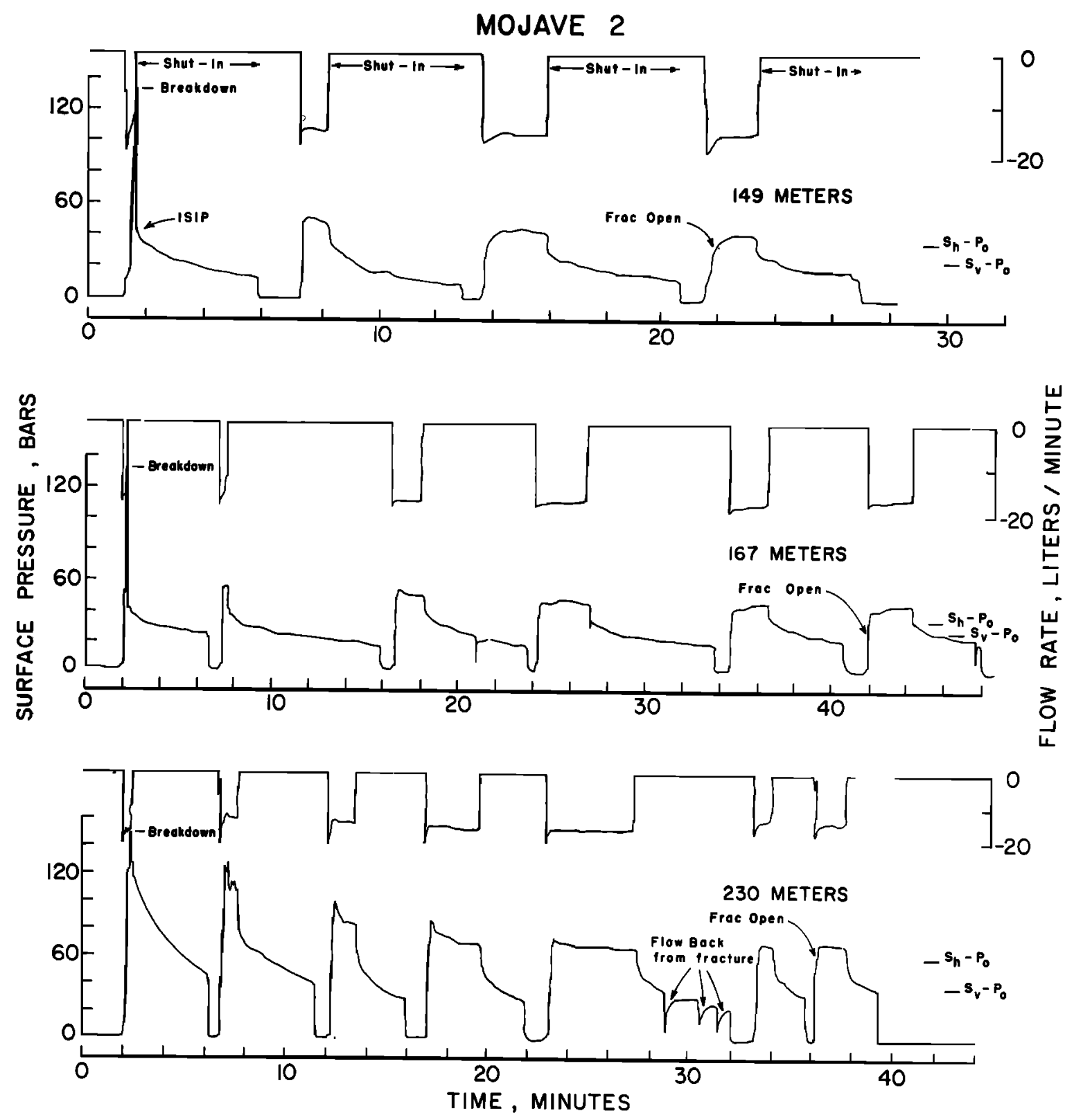

Fig. A5. Pressure and flow records from 149-, 167-, and 230-m depths in well Moj. 2.

between the breakdown pressure and fracture-opening pressure suggests that a preexisting fracture may have opened. However, both this test and that at $198 \mathrm{~m}$ yield similar values for tensile strength (see Table 1).

$L K D 198 \mathrm{~m}$. The unusual pressure variation on the fifth and sixth pressurization cycles results from intentional flow rate variations and the resultant change in the pressure gradient in the hose leading to the wellhead.

\section{Well XTLR}

Figures A4 $a$ and A4b present the data from well XTLR. These data were recorded in the same manner as the central Califor- nia profile. The most important aspect of these data is the lack of distinct breakdown and fracture-opening pressures at the greater depths. As discussed in the text, this results from the relatively high least principal stress (shut-in pressure). Examples of 'classical' behavior, that in which the breakdown pressure substantially exceeds the pumping pressure (the shutin pressure plus the pressure to overcome viscous losses in the flow system and hydraulic fracture), is seen in the 266 and 338 m records (see also the data from Moj. 2). At $561 \mathrm{~m}$, breakdown is still fairly distinct, but at the greater depths the breakdown pressure is comparable or slightly less than the pumping pressure. Other notable characteristics of the XTLR data are the following.

$X T L R 681 \mathrm{~m}$. Intermittent flow on the initial pressur- 

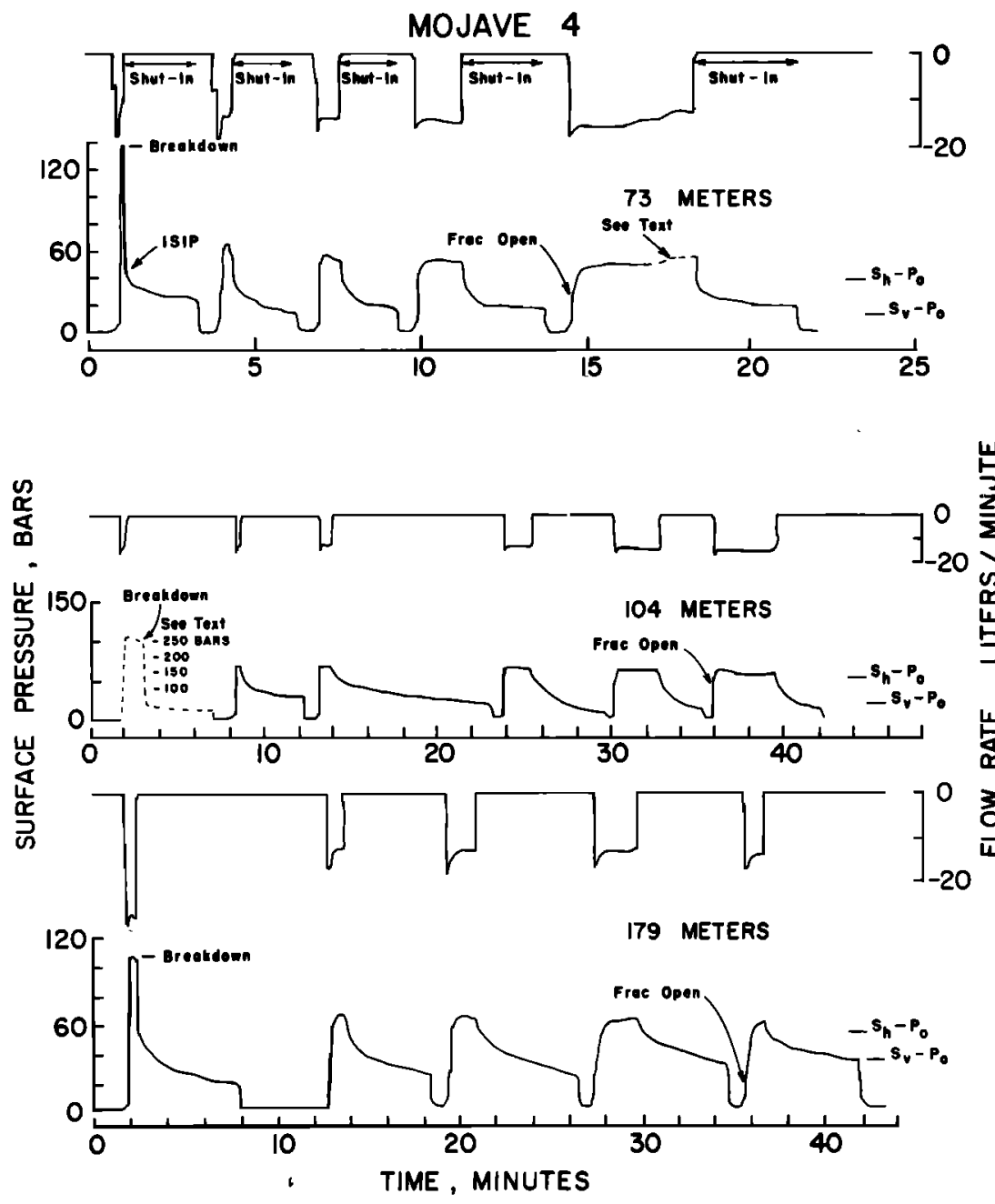

Fig. A6. Pressure and flow records from 73-, 104, and 179-m depths in Moj. 4.

ization cycle causes an erratic pressure build-up. Little flow back is observed.

$X T L R 751 \mathrm{~m}$. Fluctuation in pumping pressure on the last cycle is caused by induced variations in flow rates.

$X T L R 849 \mathrm{~m}$. The step change in pressure on the last cycle is due to the similar change in flow rate.

\section{Mojave Profile}

The pressure and flow records from the Mojave wells are presented in Figures A5-A8. These records were manually digitized tracings of analog records of uphole pressure. The 'waviness' of these records is an artifact of the digitizing and tracing procedure. Downhole pressure is obtained in the same manner as that described above. No record was made of the flow returning from the well during pressure release between cycles, but the result of choking the flow back valve can be seen on several of the records. Other notable characteristics of these records are the following.

Moj. $2230 \mathrm{~m}$. As on the LKB 199-m record, the shut-in pressure is not clear until the third cycle. During flow back after the fifth cycle the valve was choked repeatedly.
Moj. $473 \mathrm{~m}$. Pressure buildup and decrease of flow rate on the last cycle is due to accidentally pumping viscous oil from the bottom of the tank.

Moj. $4104 \mathrm{~m}$. Breakdown cycle was recorded at a scale 2.5 times that of the remainder of the record.

Moj. $5140 \mathrm{~m}$. Pressure buildup on last cycle is again due to increased viscosity of fluid.

Moj. $5216 \mathrm{~m}$. Breakdown cycle is again at 2.5 times the scale of the rest of the record. The last three cycles were pumped at progressively increasing flow rates. Correspondingly, the pumping pressures are higher (due predominantly to the pressure drop in the surface hose), but the shut-in pressure remains constant.

Moj. $180,86,134 \mathrm{~m}$. At these depths the shut-in pressure is suspiciously close to the vertical stress, implying that a horizontal fracture may have been formed. However, the values for $S_{h}$ and $S_{H}$ compare very well with the two deeper determinations.

Moj. $1218 \mathrm{~m}$. Pressure fluctuations on cycle 2 are due to a pump malfunction. The distinct pressure drop during constant rate pumping on cycle 3 is real and not caused by any apparent equipment problems. 
MOJAVE 5
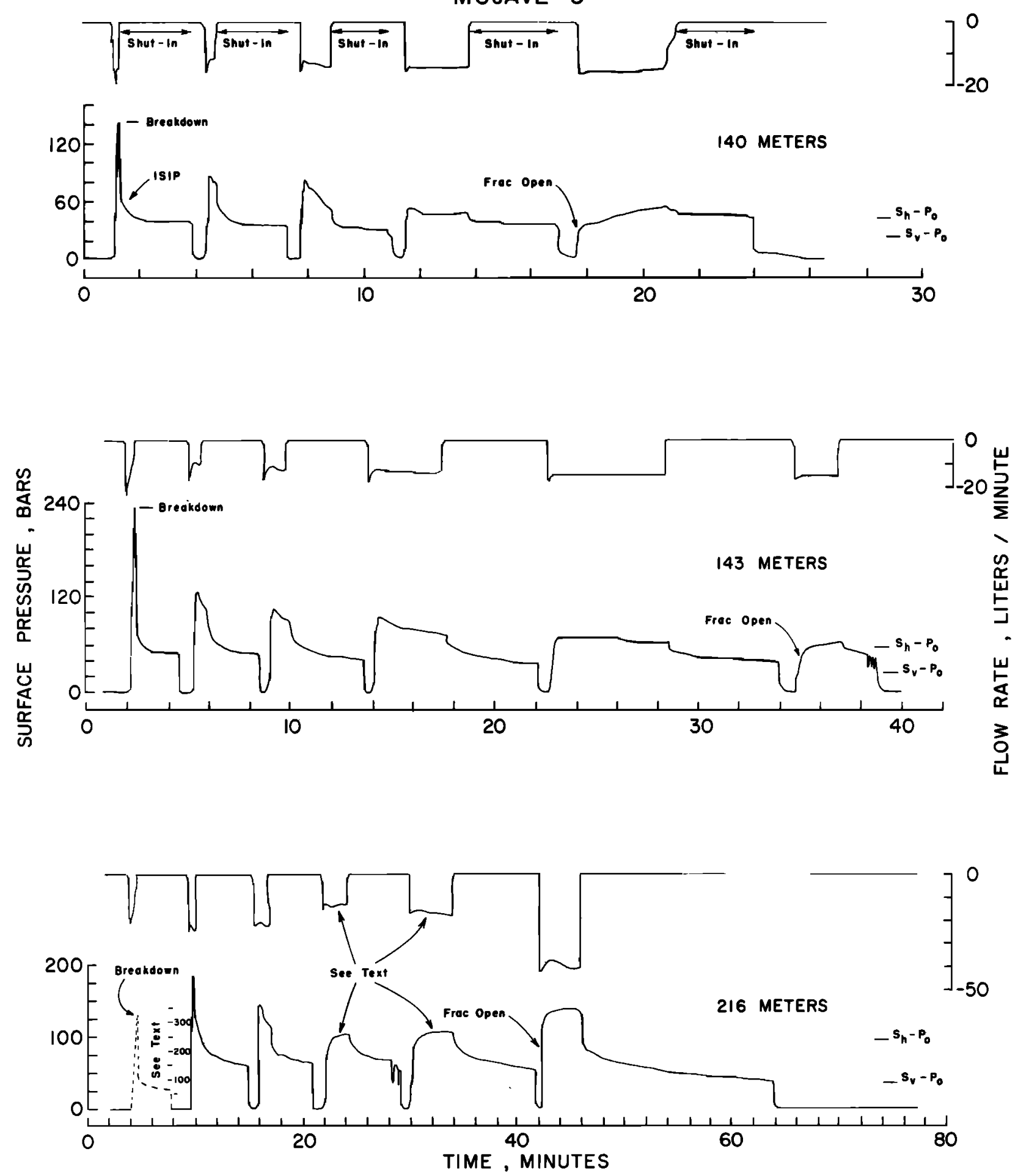

Fig. A7. Pressure and flow records from 140-, 143-, and 216-m depths in Moj. 5. 
MOJAVE ।
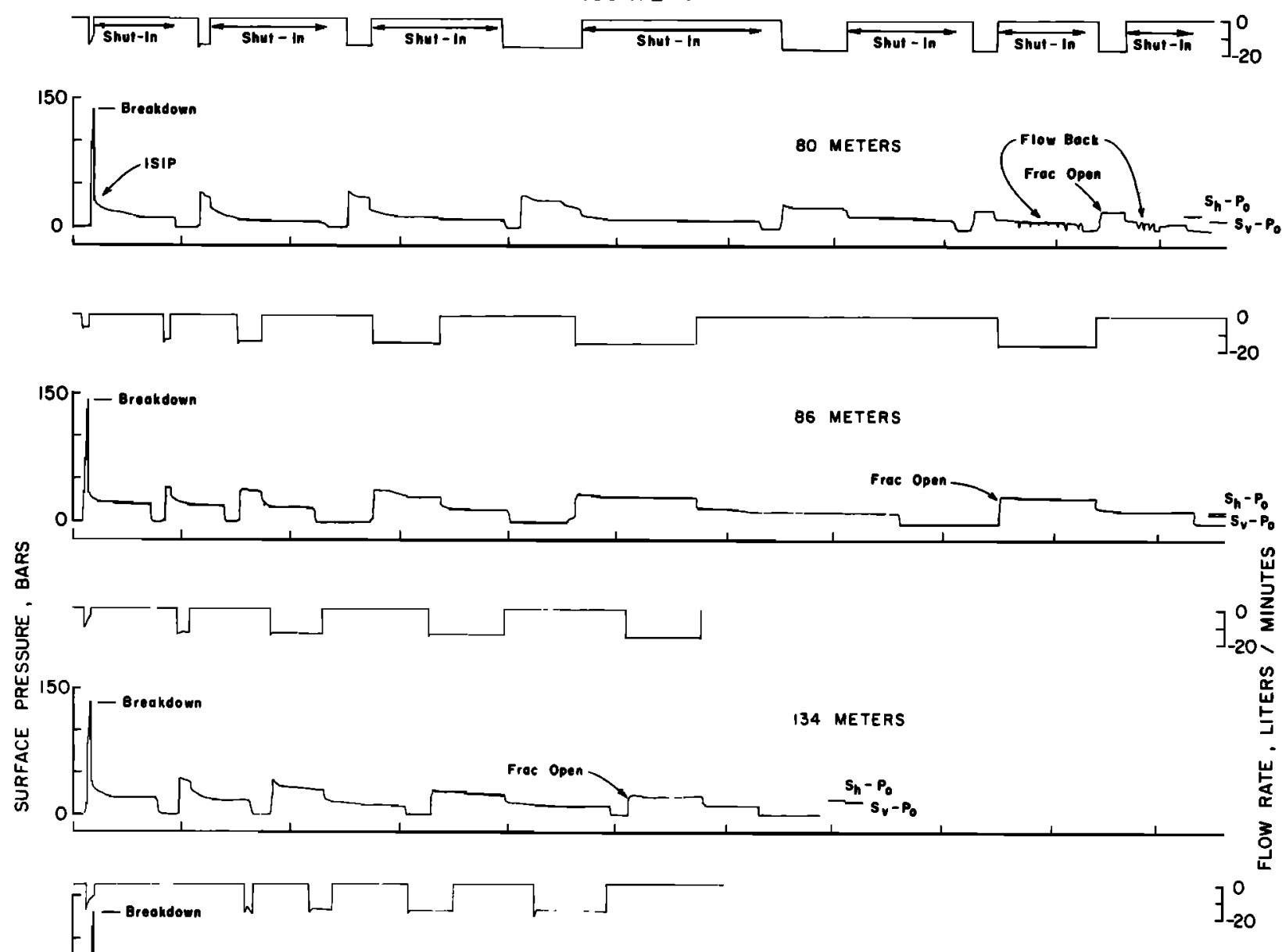

184 METERS
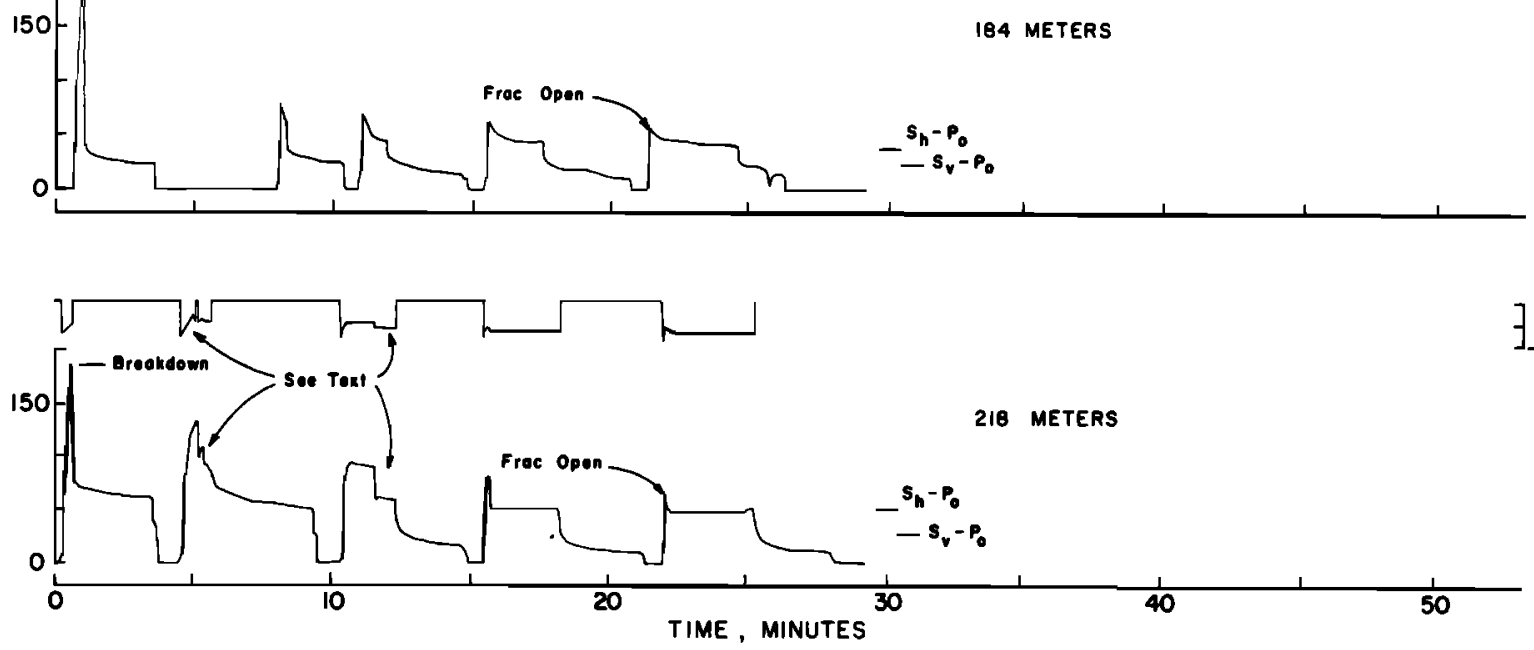

Fig. A8. Pressure and flow records from 80-, 86-, 134-, 184-, and 218-m depths in Moj. 1. 
Acknowledgments. The authors wish to thank John Roller, Joseph Svitek, and Richard Liechti for their help in these experiments. Discussions and debates with colleagues, especially Art McGarr and Tom Hanks, are appreciated, and their comments improved this manuscript.

\section{REFERENCES}

Anderson, T. O., and E. J. Stahl, A study of induced fracturing using an instrumental approach, J. Petrol. Technol., 261-267, 1967.

Bredehoeft, J. D., R. G. Wolf, W. S. Keys, and E. Shuter, Hydraulic fracturing to determine the regional in-situ stress field Piceance $\mathrm{Ba}$ sin, Colorado, Geol. Soc. Amer. Bull., 87, 250-258, 1976.

Haimson, B. C., Near-surface and deep hydrofracturing stress measurements in the Waterloo quartzite, paper presented at the 19th U.S. Symposium on Rock Mechanics, Univ. of Nev., Reno, 1978.

Haimson, B., and C. Fairhurst, In-situ stress determinations at great depths by means of hydraulic fracturing, in Proceedings of the Elev. enth Symposium on Rock Mechanics, edited by W. H. Somerton, pp. 559-584, American Institute of Mechanical Engineers, New York, 1970.

Haimson, B. C., J. LaComb, S. J. Green, and A. H. Jones, Deep stress measurements in tuff at the Nevada Test Site, in Advances in Rock Mechanics, vol. IIa, pp. 557-561, National Academy of Science, Washington, D. C., 1974.

Hanks, T. C., Crustal earthquake stress drops, Proceedings of Conference IX, Magnitude of Deviatoric Stresses in the Earth's Crust and Upper Mantle, Open File Rep. 80-625, pp. 490-518, U.S. Geol. Surv., Reston, Va., 1980.

Hubbert, M. K., and D. G. Willis, Mechanics of hydraulic fracturing, J. Petrol. Technol., 9, 153-168, 1957.

Lachenbruch, A. H., and J. H. Sass, Thermo-mechanical aspects of the San Andreas fault system, in Proceedings of the Conference on Tectonic Problems of the San Andreas Fault System, edited by R. L. Kovach and A. Nur, pp. 192-205, Stanford University Publications, Stanford, Calif., 1973.
Lachenbruch, A. H., and J. H. Sass, Heat flow and energetics of the San Andreas fault zone, $J$. Geophys. Res., this issue, 1980.

McGarr, A., Some constraints on levels of shear stress in the crust from observations and theory, J. Geophys. Res., this issue, 1980.

McGarr, A., and N. C. Gay, State of stress in the earth's crust, $A n n$. Rev. Earth Planet. Sci., 6, 405-436, 1978.

Sbar, M. L., T. Engelder, R. Plumb, and S. Marshak, Stress pattern near the San Andreas fault, Palmdale, California, from near-surface in situ measurements, $J$. Geophys. Res., 84, 156-164, 1979.

Tullis, T. E., Stress measurements by shallow overcoring near the San Andreas fault, Geol. Soc. Amer. Mem., in press, 1980.

Zemanek, J., R. L. Caldwell, E. E. Glenn, Jr., and L. J. Norton, Formation evaluation by inspection with the borehole televiewer, Geophysics, 35(2), 254-269, 1970.

Zoback, M. D., and D. D. Pollard, Hydraulic fracture propagation and the interpretation of pressure-time records for in-situ stress measurements, paper presented at the 19th U.S. Symposium on Rock Mechanics, Univ. of Nevada, Reno, 1978.

Zoback, M. D., and J. C. Roller, Magnitude of shear stress on the San Andreas fault: Implication from a stress measurement profile at shallow depth, Science, 206, 445-447, 1979.

Zoback, M. D., J. Healy, and J. Roller, Preliminary stress measurements in central California using the hydraulic fracturing technique, Pure Appl. Geophys., 115, 135-152, 1977.

Zoback, M. D., J. C. Roller, J. Svitek, and D. Seeburger, Hydraulic fracturing stress measurements and the magnitude of shear stress on the San Andreas fault in southern California, Proceedings of Conference IX, Magnitude of Deviatoric Stresses in the Earth's Crust and Upper Mantle, Open File Rep. 80-625, pp. 490-518, U.S. Geol. Surv., Reston, Va., 1980.

Zoback, M. L. C., and M. D. Zoback, State of stress in the conterminous United States, J. Geophys. Res., this issue, 1980.

(Received November 26, 1979; revised August 4, 1980; accepted August 15, 1980.) 